\title{
Early uptake of specific symbionts enhances the post-settlement survival of Acropora corals
}

\author{
Go Suzuki ${ }^{1, *}$, Hiroshi Yamashita ${ }^{1}$, Sayaka Kai ${ }^{1}$, Takeshi Hayashibara ${ }^{1}$, \\ Kiyoshi Suzuki ${ }^{2}$, Yukihiro Iehisa ${ }^{2}$, Wataru Okada ${ }^{3}$, Wataru Ando ${ }^{4}$, Takeshi Komori ${ }^{5}$ \\ ${ }^{1}$ Ishigaki Tropical Station, Seikai National Fisheries Research Institute, 148-446 Fukai-Ota, Ishigaki, Okinawa 907-0451, Japan \\ ${ }^{2}$ Engineering Division, Daikure Co. Ltd., 1-24 Tsukiji-cho, Kure, Hiroshima 737-8513, Japan \\ ${ }^{3}$ Coastal Environmental Design Division, ECOH Co. Ltd., 1-10-5 Tahara, Naha, Okinawa 901-0156, Japan \\ ${ }^{4}$ Fisheries Infrastructure Development Center, 2-14-5 Tukiji, Chuo-ku, Tokyo 104-0045, Japan \\ ${ }^{5}$ Fisheries Agency, Ministry of Agriculture, Forestry and Fisheries, 1-2-1 Kasumugaseki, Chiyoda-ku, Tokyo 100-8907, Japan
}

\begin{abstract}
For corals that establish symbioses with dinoflagellate Symbiodinium spp. at the larval stage or later through horizontal transmission, the ecological significance of the early uptake of algal symbionts remains unknown. It has been hypothesized that early uptake of symbionts is an advantage for long-distance dispersal. Here, we tested the hypothesis that early acquisition of symbionts enhances post-settlement survival. We used a cultured strain of clade A Symbiodinium that was isolated from wild Acropora spat as the algal symbiont. Symbiotic and aposymbiotic Acropora larvae were prepared in the laboratory and settled on experimental plates in the field. The survival of settlers was monitored for 15 mo. Our results showed that more larval-stage settlers harbouring symbionts survived than those without, even when there was no difference in the initial density of settled larvae. We analysed the Symbiodinium clades harboured by the corals at 1 mo after settlement, and found that clade A was less abundant in the corals that grew from aposymbiotic larvae than in those that developed from symbiotic larvae. There was also a marked difference in coral survival between aposymbiotic and symbiotic larvae over this period. The higher survival rate of 'early uptake' corals was more pronounced on shaded plates. These results suggest that the early uptake of specific symbionts enhances post-settlement survival in dark places such as reef crevices, which are sites commonly settled by coral larvae.
\end{abstract}

KEY WORDS: Coral-algal symbiosis - Horizontal transmission ' Self-recruitment · Symbiodinium $\cdot$ Coral restoration

\section{INTRODUCTION}

Larval recruitment of reef corals is one of the key factors in the rehabilitation of highly degraded coral communities (Hughes \& Tanner 2000, Hughes et al. 2005, Coles \& Brown 2007). Although recruitment patterns of coral larvae have been reported in many regions around the world (e.g. Hughes et al. 1999, Edmunds 2000, Glassom et al. 2004), few studies have focused on the initial establishment of their symbiosis with dinoflagellate algae in the genus Symbiodinium.
Most corals take up symbionts during the pre- and post-settlement stages, when the mortality of corals is likely to be very high (Wilson \& Harrison 2005). During these initial stages of coral recruitment, the efficient use of solar radiation is critical for survival because the corals rely on the photosynthetic products from the symbionts (Muscatine et al. 1981, Rinkevich 1989). To understand the ecological aspects of the initial establishment of the coral-algal symbiosis, it is essential to consider the relationships among coral, algae, and the light environment. 
Reef corals can be classified into 2 groups according to their method of acquiring their symbionts: vertical and horizontal transmitters (Trench 1987). Vertical transmitters inherit symbionts from adult corals during the egg stage (Hirose et al. 2001), whereas horizontal transmitters acquire symbionts from an environmental pool during the larval and juvenile stages. Coral larvae are able to take up symbionts only after formation of the mouth (i.e. 3 to $4 \mathrm{~d}$ after fertilization) (Schwarz et al. 1999, Adams et al. 2009, Harii et al. 2009, but see also Marlow \& Martindale 2007). While these results showed that corals at the swimming larval stage begin to take up symbionts, the ecological significance of early uptake (i.e. acquisition of algal symbionts at the pre-settlement stage) is largely unknown. It has been hypothesized that early uptake of symbionts supports long-distance dispersal, with the energy for swimming provided via the photosynthetic activity of the symbionts (Harii et al. 2010, Cumbo et al. 2013). Thus, the early uptake of symbionts would likely be an advantage for coral larvae that disperse over long distances. However, there is some evidence that self-recruitment, rather than long-range dispersal, is the main strategy for population maintenance of marine sedentary organisms such as corals (Sammarco \& Andrews 1988, Jones et al. 1999, 2009, Cowen et al. 2000, Poulin et al. 2002, Shanks \& Shearman 2009, Underwood et al. 2009). Considering this evidence, it is unlikely that the early uptake of symbionts by corals is linked only with long-distance dispersal.

Here, we present another hypothesis: that the early uptake of symbionts by coral larvae enhances postsettlement survival. To test this hypothesis, we prepared 2 groups of coral larvae, one with and one without symbionts, and compared their survival for 15 mo after settlement in the field.

The Symbiodinium algal symbionts can be classified into 9 groups (clades A-I) based on their genotype (Pochon \& Gates 2010). Each clade comprises various subclades, and there can be differences in the physiological characteristics of the alga, even among those in the same clade (Sampayo et al. 2008). In some species of corals, the juveniles and adults harbour different Symbiodinium clades (Abrego et al. 2009, Yamashita et al. 2013). In this study, we prepared a strain of a specific Symbiodinium type (A1 type) isolated from a wild flat-shaped Acropora juvenile (Yamashita \& Koike 2013), and inoculated it into coral larvae before seeding. In an artificial uptake experiment, this strain was more readily taken up by young Acropora larvae (4 d after the fertilization) than was clade $\mathrm{C}$, which is dominant in adult corals
(H. Yamashita et al. unpubl. data). Hence, clade A1 is considered to be one of the types of Symbiodinium most readily taken up by corals at the swimming larval stage.

The optimal light environment for coral recruits may change with increasing algal density within the host. That is, when the algal density is zero or very low, the host corals would not require sunlight because they could not rely on photosynthetic products from the alga. However, they would require sunlight as the algal density increases and the alga begins to contribute to coral growth. It takes a few months after settlement for the algal density to increase to a level where the alga can provide sufficient energy resources for the host (e.g. Hayashibara et al. 1997). Hence, we used different light conditions to compare the effects of different periods of shading on initial coral survival. These comparisons allowed us to determine whether the optimal light environment for coral recruits varied according to the timing of initial uptake of symbionts (pre- or post-settlement).

\section{MATERIALS AND METHODS}

\section{Preparation of experimental plates}

Studying the initial survival of corals under natural conditions is challenging because coral recruits are subject to multiple factors with complex interactions. At present, fish grazing and sedimentation are considered to be the dominant factors in the initial high mortality of coral settlers (Babcock \& Davies 1991, Birrell et al. 2005, Nozawa 2008, Baria et al. 2010). To determine the effect of different light conditions on coral survival, we used artificial plates with a lattice structure as the settlement substratum for corals. Using these plates, 10 times more settled spat survived for 6 mo in the natural environment than survived in similar conditions in previous experiments (Suzuki et al. 2011b), largely because the lattice structure of the plates reduced fish grazing and sedimentation.

The experiments were conducted at Sekisei Lagoon $\left(24^{\circ} 18^{\prime} \mathrm{N}, 123^{\circ} 59^{\prime} \mathrm{E}\right)$, in the Ryukyu Archipelago in southern Japan. We used experimental plates with grid sizes of $2.5 \mathrm{~cm}$ or $4 \mathrm{~cm}$, because the grid size was shown to affect coral spat survival in a previous study (Suzuki et al. 2011b). Grid plates were made of fiberglass-reinforced plastic (FRP) and measured $40 \times 40 \mathrm{~cm}$ or $25 \times 25 \mathrm{~cm}$. The plates were secured at 6 different depths on the reef slope (5 to 18 m; Table 1) of the lagoon in April 2011. 
Table 1. Light intensity ( $\mu \mathrm{mol}$ photons $\mathrm{m}^{-2} \mathrm{~s}^{-1}$ ) at 6 depths measured every $10 \mathrm{~min}$ during the daytime $(10: 00 \mathrm{~h}$ to 16:00 h) on 3 clear days in June 2011 (mean \pm SD). Light intensity under the shading treatment was measured at 2 depths: 5 and $18 \mathrm{~m}$. Numbers in parentheses indicate transmittance (\%) of shade board. NB Light intensity under shade at $18 \mathrm{~m}$ was measured in August because of technical problems

\begin{tabular}{|lcc|}
\hline Depth $(\mathrm{m})$ & Unshaded & Shading \\
\hline 5 & $1020.9 \pm 244.6$ & $118.8 \pm 15.8(11.6)$ \\
6 & $937.6 \pm 195.3$ & - \\
9 & $674.6 \pm 124.3$ & - \\
12 & $488.6 \pm 86.9$ & - \\
15 & $306.3 \pm 59.1$ & $44.9 \pm 19.1(21.3)$ \\
18 & $292.1 \pm 59.1$ & \\
\hline
\end{tabular}

A total of 180 plates was prepared (90 for each grid size). The plates were allocated to a control (i.e. no larval seeding) or 1 of 7 different seeding treatments: (1) seeding only, (2) shading only, (3) grazing guard only, (4) shading and grazing guard, (5) 1 mo shading, (6) 3 mo shading, or (7) 7 mo shading. Two plates of each grid size were prepared for each treatment at each depth (i.e. for the symbiotic and aposymbiotic coral larvae), with 1 plate of each grid size for the 'no seeding' control at each depth. In the 'shading' treatment, 80 to $90 \%$ of the ambient light was blocked by a blue-transparent polyvinyl plate (1 mm thickness) set $20 \mathrm{~cm}$ above the grid plate (Fig. 1). In the 'grazing guard' treatment, the grid opening was narrowed by stretching fishing line around the grid plate $(4 \mathrm{~cm}$ grid plate only). In the treatments where shading was provided for a fixed period, the shade board was

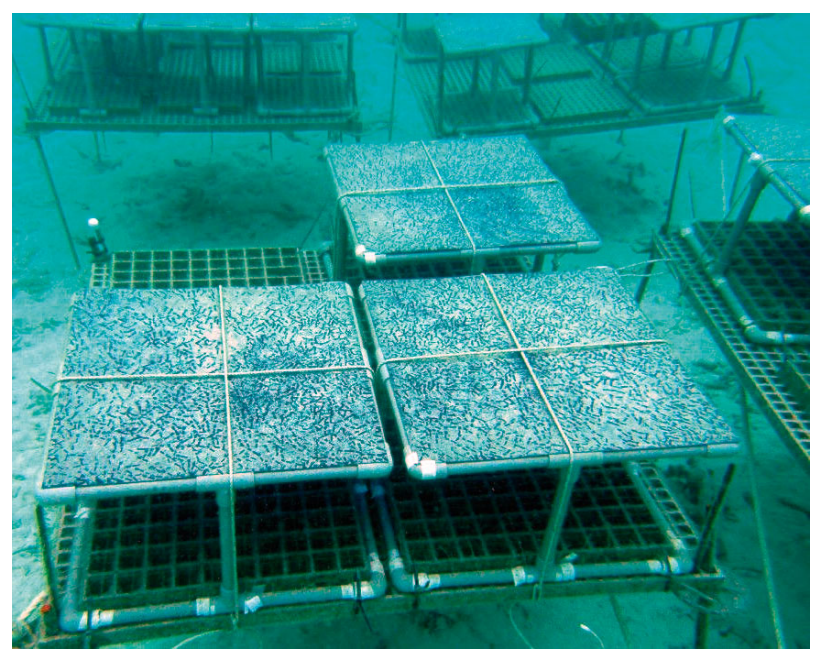

Fig. 1. Grid plates with the 'shading' treatment at the study site removed 1,3 , or 7 mo after seeding. The grid plates were positioned randomly at each depth to avoid pseudo-replication. A number of small cuts were made in advance on each grid plate to allow a small piece $(3 \times 4 \mathrm{~cm})$ to be sampled from each plate and brought back to the laboratory to count the number of settled and living corals. Eight photometers (model MDS-MkV/L, JFE Advantech) were installed to record the light levels at each depth.

\section{Larval collection and artificial uptake of symbionts}

We used Acropora corals in this study, the most diverse and dominant group of corals on Indo-Pacific reefs. All species in this genus gain their symbionts via horizontal transmission. Most Acropora larvae drift for at least 2 to $3 \mathrm{~d}$ and settle about 5 to $10 \mathrm{~d}$ after fertilization (Morse et al. 1996, Nozawa \& Harrison 2008, Suzuki et al. 2011a). As a result, a higher proportion of spawned Acropora larvae settle on reefs close to their natal reef, and a lower proportion are dispersed over long distances (Underwood et al. 2009).

We collected 15 mature colonies of the branching coral Acropora yongei 1 wk before the expected date of mass spawning in early May 2011. The colonies were placed in tanks, and after $24 \mathrm{~h}$, hydrogen peroxide solution was used to stimulate spawning (Hayashibara et al. 2004). The released bundles were collected and conspecific gametes were mixed and fertilized. The fertilized eggs were reared for the first $4 \mathrm{~d}$ in eight $100 \mathrm{l}$ tanks filled with filtered seawater ( $2 \mu \mathrm{m}$ filter). The larval density in the tanks was 500 to 1000 larvae $\mathrm{l}^{-1}$. The filtered seawater was exchanged periodically.

The symbiont for early uptake was a cultured strain of clade A Symbiodinium (AJIS2-C2) isolated from a wild Acropora juvenile (approximately $1.5 \mathrm{yr}$ old) the previous year (Yamashita \& Koike 2013). This strain was readily taken up by coral larvae even when the cell density of the alga in ambient waters was very low (H. Yamashita et al. unpubl. data). We added 2 or 5 algal cells per larva (approximately 2 to 4 cells ml ${ }^{-1}$ ) to half of the tanks containing 2 and $3 \mathrm{~d}$ old larvae (500 to 1000 larvae $1^{-1}$ ), respectively. No algae were added to the other 4 tanks. Immediately before larval seeding, we randomly sampled 10 larvae from each treatment and observed whether the symbiont had been taken up under a fluorescence microscope. The uptake rate for tanks with and without the alga was $70 \%$ and $0 \%$, respectively.

Groups of 20000 larvae that were competent to settle and that had moved to the bottom of the tank (age 
$4 \mathrm{~d})$ were removed and placed into a nylon bag. A total of 24 bags were transferred to the experimental site by boat (90 min duration). Divers enclosed 7 plates in each bag (4 bags for each depth) to avoid diffusion of larvae. The nylon bags were removed $48 \mathrm{~h}$ later, at which point larval seeding was considered to be complete. Then, each grid plate was set horizontally on a grid-structured foundation that was raised $50 \mathrm{~cm}$ above the seafloor.

\section{Estimation of juvenile survival}

To estimate the number of corals that initially settled on the grid plates, 5 pieces $\left(24 \mathrm{~cm}^{2}\right.$ of the observed surface area of each piece $=2.5 \%$ of the total surface) were collected from each plate (avoiding the bias of distribution of collected pieces) $48 \mathrm{~h}$ after larval seeding was completed (i.e. the nylon bags were removed). The initial status of coral settlement and survival was determined for only the 5 following treatments (only the $4 \mathrm{~cm}$ grid plates): no seeding, seeding only, shading only, grazing guard only, shading and grazing guard. The number of settled corals was estimated by counting the number of corals on the grid pieces. The number of surviving corals was estimated by the same method 1 and 3 mo after larval seeding. The collected pieces were transferred to the laboratory in seawater and the number of live and dead (only skeletons remaining) corals was counted under a stereo microscope. The mean number of corals on the 5 collected pieces was used to calculate the mean number of corals on the grid plate. The survival rate for each plate was estimated as follows: number of live corals/number of initially settled corals. To identify the genetic type of the symbiont, 1 or 2 juvenile corals from each piece (20 to 30 corals per experimental plate) were removed with a small knife and preserved individually in guanidine solution for DNA extraction.

To estimate the number of live corals at 7 and 15 mo after larval seeding, divers counted all juvenile corals visible to the naked eye (more than $5 \mathrm{~mm}$ diameter) on the grid plates for all treatments.

\section{Identification of Symbiodinium clades in juvenile corals}

The whole bodies of corals that survived 1 and 3 mo after settlement (96 specimens in total) were digested in $30 \mu \mathrm{l}$ guanidine solution for several days. An equal volume of phenol extraction buffer (PEB) was added to the guanidine solution just before DNA extraction. Total DNA was extracted from the guanidine solution with PEB by phenol/chloroform extraction and ethanol precipitation. The DNA was then resuspended in TE buffer. The clade compositions of Symbiodinium within the juvenile corals were determined by clade-specific PCR using Symbiodinium clade A- to F-specific PCR primer sets targeting the nuclear 28S rRNA gene (28S rDNA) region (Yamashita et al. 2011). Only clades A, C, and D were detected from the environment (water columns, sediments, and adult corals) (Yamashita et al. 2013). Therefore, the extracted DNA was amplified using clade A-, C-, and D-specific PCR primer sets. Each PCR mixture contained $1 \mathrm{pmol} \mathrm{pl}^{-1}$ of each forward and reverse primer, the recommended volume of TaKaRa Taq ${ }^{\mathrm{TM}}$ Hot Start Version (TaKaRa Bio), and extracted DNA at one-tenth of the total reaction volume. PCRs were performed using a thermal cycling protocol of 1 cycle at $94^{\circ} \mathrm{C}(5 \mathrm{~min}), 30$ cycles at $94^{\circ} \mathrm{C}$ $(10 \mathrm{~s}), 61^{\circ} \mathrm{C}(30 \mathrm{~s})$, and $72^{\circ} \mathrm{C}(30 \mathrm{~s}) ;$ and $1 \mathrm{cycle}$ at $72^{\circ} \mathrm{C}$ (5 min) in a Gene Amp ${ }^{\circledR}$ PCR System 9700 (PE Applied Biosystems). An equivalent to 1 cell reaction $^{-1}$ of DNA extracted from each Symbiodinium clade culture strain was used as a positive control. The PCR products were separated by agarose gel electrophoresis on $2.0 \%$ agarose gels (TaKaRa Bio) and stained with ethidium bromide. Positively amplified samples were inspected under a UV transilluminator to identify both clade and individual coral specimens, with reference to a positive control. In these PCR systems, minor background clades could be detected in the DNA at the level of $0.1 \%$ for clades A, C, and D (Yamashita et al. 2011).

\section{Statistical analyses}

Differences in the number of settled and surviving corals between the groups of plates seeded with symbiotic or aposymbiotic larvae were analysed using a 2 -sample $t$-test. The number of corals in all plate treatments except the 'no seeding' treatment was pooled for this analysis. Next, the differences in the number of corals that settled and survived among plate treatments (and also among depths) were analysed using 1-way ANOVA. The Bonferroni $t$-test was performed for multiple comparisons. The null hypothesis $\left(H_{0}\right)$ was that there was no variation in the number of corals among plate treatments and depths. We treated plate treatment and depth as factors (i.e. 6 replicates for plate treatments and 4 or 7 replicates for depth) and the number of settled and surviving 
corals per unit area on the plate as the variable. The number of corals at all depths (or for all plate treatments) was pooled in this analysis. All statistical tests were performed using SYSTAT v. 11 software. In addition, the genetic clade composition of Symbiodinium within corals surviving at 1 and 3 mo after settlement was compared between groups seeded with symbiotic or aposymbiotic larvae by 1-way analysis of similarities using Primer v. 5 software. Depth was treated as a replicate in this analysis (i.e. 6 replicates). The number of permutations was 999, and calculations were made of global $\mathrm{R}$ and the significance level of rejecting the null hypothesis to establish that there were no differences between the groups. Results are expressed as means $\pm \mathrm{SD}$.

\section{RESULTS}

\section{Initial settlement of corals}

The mean number of settled corals on the seeded plates was $13.37 \pm 11.17$ per $100 \mathrm{~cm}^{2}$ in the symbiotic larval group and $14.69 \pm 12.56$ in the aposymbiotic larval group. There was no significant difference between the 2 groups ( $t$-test, $p=0.546$; Fig. $2 \mathrm{a}$ ). On
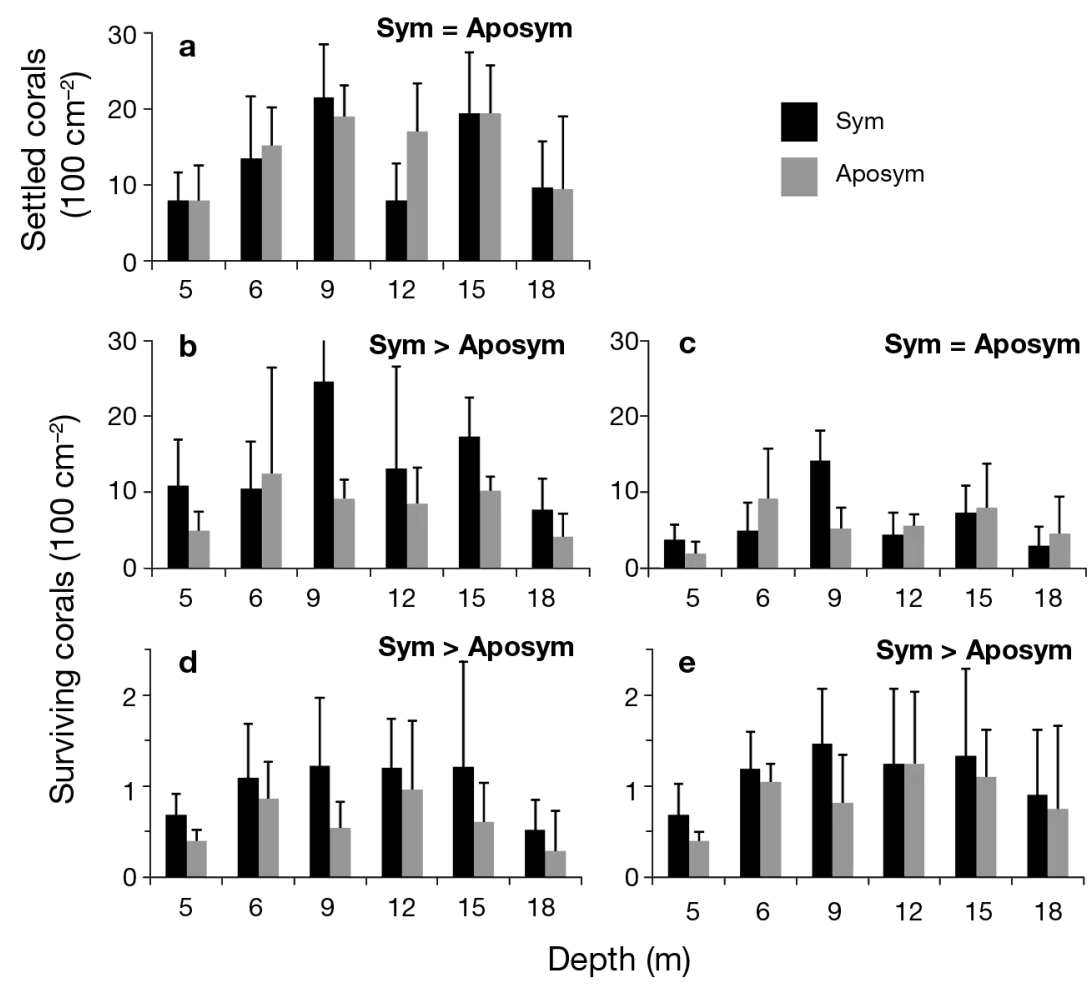

Fig. 2. Mean (+SD) number of (a) settled and live corals at (b) 1, (c) 3, (d) 7 and (e) 15 mo after settlement derived from symbiotic (dark grey) and aposymbiotic (light grey) larvae at each depth. The data from all plate treatments were pooled for this analysis: $(\mathrm{a}-\mathrm{c}) \mathrm{n}=4,(\mathrm{~d}, \mathrm{e}) \mathrm{n}=7$ the 'no seeding' plate, the number of settled corals was $1.85 \pm 2.56$ per $100 \mathrm{~cm}^{2}$. These were corals that recruited naturally before the small pieces were collected. The number of settled corals varied among the different depths $(\mathrm{p}<0.05)$, with significantly fewer settled corals at the shallowest $(5 \mathrm{~m})$ and deepest $(18 \mathrm{~m})$ depths than at $9 \mathrm{~m}$ and $15 \mathrm{~m}$ depths. There were no significant differences in the number of settled corals among the plate treatments $(p>0.05$; Fig. 3a).

\section{Survival of corals 1 and 3 mo after settlement}

The mean number of corals surviving 1 mo after settlement was $13.99 \pm 13.39$ in the symbiotic larval group and $8.26 \pm 9.61$ in the aposymbiotic larval group; the survival rates were $104.7 \%$ and $56.2 \%$, respectively. Significantly higher survival rates were observed on plates seeded with symbiotic larvae (the early uptake condition) than on those seeded with aposymbiotic larvae ( $p=0.013$; Fig. $2 b$ ). However, by 3 mo post-settlement this difference was no longer significant ( $\mathrm{p}=0.7$; Fig. $2 \mathrm{c}$ ). The number of corals surviving at that point had decreased by nearly half to $6.25 \pm 7.58$ in the symbiotic larval group and $5.73 \pm 6.85$ in the aposymbiotic larval group during the 2 mo from June to August. There were no differences among plate treatments $(\mathrm{p}>0.05$; Fig. 3b,c).

\section{Survival of corals 7 and 15 mo after settlement}

On the $4 \mathrm{~cm}$ grid plates, the mean number of corals surviving 7 mo after settlement was $1.07 \pm 0.76$ per $100 \mathrm{~cm}^{2}$ in the symbiotic larval group and $0.65 \pm 0.52$ in the aposymbiotic larval group. On the $2.5 \mathrm{~cm}$ grid plates, which were not observed until 7 mo after settlement, the number of surviving corals was $1.05 \pm 0.99$ in the symbiotic larval group and $0.66 \pm 0.82$ in the aposymbiotic larval group. There were significantly more surviving corals on plates settled by symbiotic larvae than on those settled by aposymbiotic larvae for 


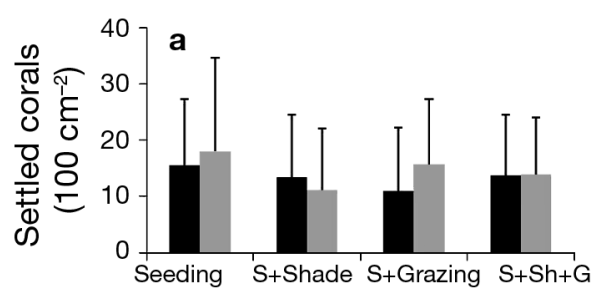

Sym

Aposym
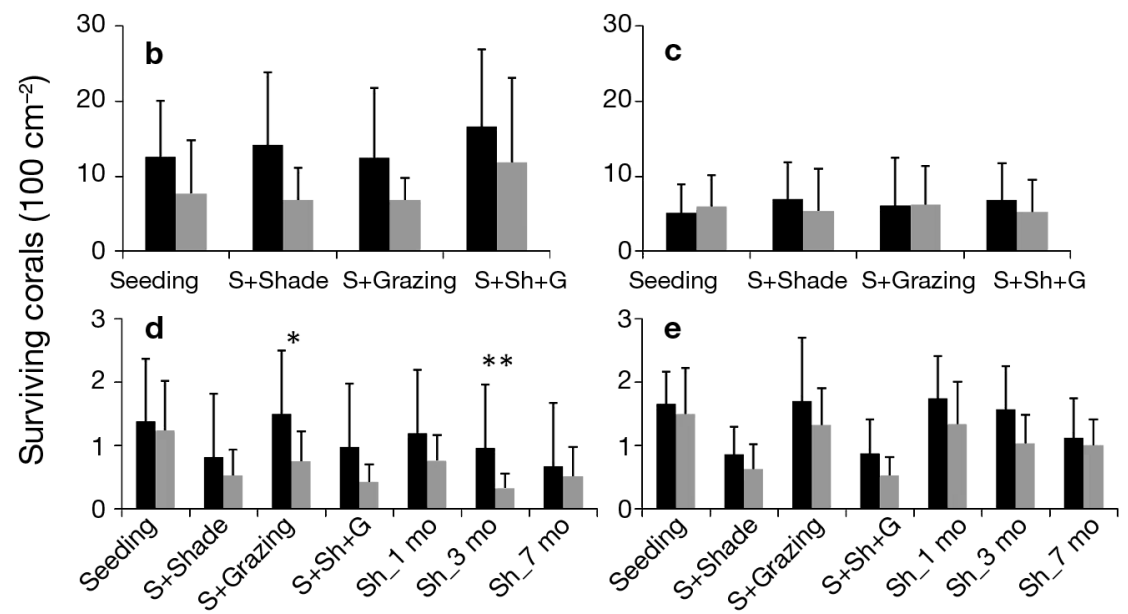

Fig. 3. Mean (+SD) number of (a) settled and live corals at (b) 1, (c) 3, (d) 7 and (e) 15 mo after settlement derived from symbiotic (dark grey) and aposymbiotic (light grey) larvae in each treatment (S: Seeding; Sh: Shading; G: Grazing guard). Significant difference between symbiotic (dark grey) and aposymbiotic (light grey) larval groups was found in 'S + Grazing' and 'Sh_3 mo' treatments at 7 mo after settlement, when the counts of corals at all depths were pooled $(n=6)$. Asterisks indicate significant differences between the 2 larval groups $\left(t\right.$-test $\left.{ }^{*} \mathrm{p}<0.1,{ }^{* *} \mathrm{p}<0.05\right)$

both the $2.5 \mathrm{~cm}$ and $4 \mathrm{~cm}$ grid plates $(t$-test, $\mathrm{p}=0.004$ and 0.041, respectively; Fig. 2d). Also, the magnitude of the difference in the number of surviving corals between symbiotic and aposymbiotic conditioned plates varied among the plate treatments: in the 'shading and grazing guard' and ' 3 mo shading' treatments; more corals derived from symbiotic larvae survived than did those derived from aposymbiotic larvae ( $t$-test, $\mathrm{p}<0.1$ ) (Fig. 3d). However, there was no difference in survival rates of corals between symbiotic and aposymbiotic conditioned plates in the 'seeding only' treatment at any time (Fig. 3).

At 15 mo post-settlement, the average number of surviving corals was $1.36 \pm 0.71$ in the symbiotic group and $1.05 \pm 0.59$ in the aposymbiotic group on the $4 \mathrm{~cm}$ grid plates, and $1.13 \pm 0.82$ in the symbiotic group and $0.81 \pm 0.73$ in the aposymbiotic group on the $2.5 \mathrm{~cm}$ grid plates. The number of corals at $15 \mathrm{mo}$ was slightly higher than that at 7 mo because the corals were larger at 15 mo (i.e. divers might have overlooked small colonies at $7 \mathrm{mo}$ ). The average number of surviving corals was $1.5 \pm 0.7$ in the 2 treatments without shading ('seeding only' and 'grazing guard only') and $0.8 \pm 0.4$ in the 3 treatments with long-term shading ('shading only', 'shading and grazing guard' and ' 7 mo shading'). That is, the longer the period of shading, the fewer corals survived (Fig. 4). The average number of surviving corals on the 'no seeding' plates (i.e. naturally settled and survived corals) was $0.1 \pm 0.1$ (negligibly low level). Comparing the symbiotic and aposymbiotic groups, there was a higher rate of coral survival of the former group than the latter group on both the $2.5 \mathrm{~cm}$ and $4 \mathrm{~cm}$ grid plates $(\mathrm{p}=$ 0.034 and $\mathrm{p}=0.031$, respectively; Fig. 2e).

\section{Genetic typing of symbionts}

Corals surviving 1 and 3 mo after settlement harboured Symbiodinium clades A, C and D, and most harboured multiple clades within a single spat. At 1 mo after settlement, $95 \%$ of the 'early uptake' conditioned corals harboured clade D while $67 \%$ of those corals harboured clade $\mathrm{A}$, even though the latter was the cultured strain added to the larvae (uptake rate at seeding was $70 \%$ ). The dominant Symbiodinium type within the 'no symbiont' conditioned corals at 1 mo after settlement was also clade $D_{;} 95 \%$ of those corals harboured clade D while $43 \%$ of them har-

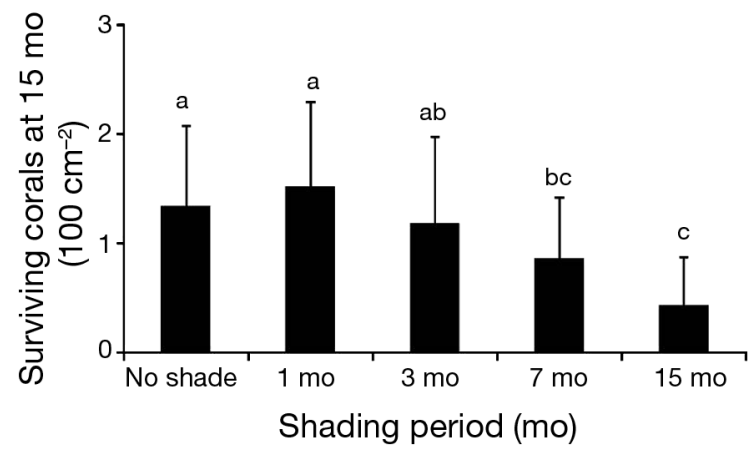

Fig. 4. Mean $(+\mathrm{SD})$ number of live corals under different shading treatments at 15 mo after settlement. Shade board was removed after $1,3,7$, and 15 mo in the 4 treatments. Lower-case letters indicate significant differences among treatments (Bonferroni's test). Number of corals in symbiotic and aposymbiotic larval groups and from all depths were pooled for this analysis $(\mathrm{n}=12)$ 


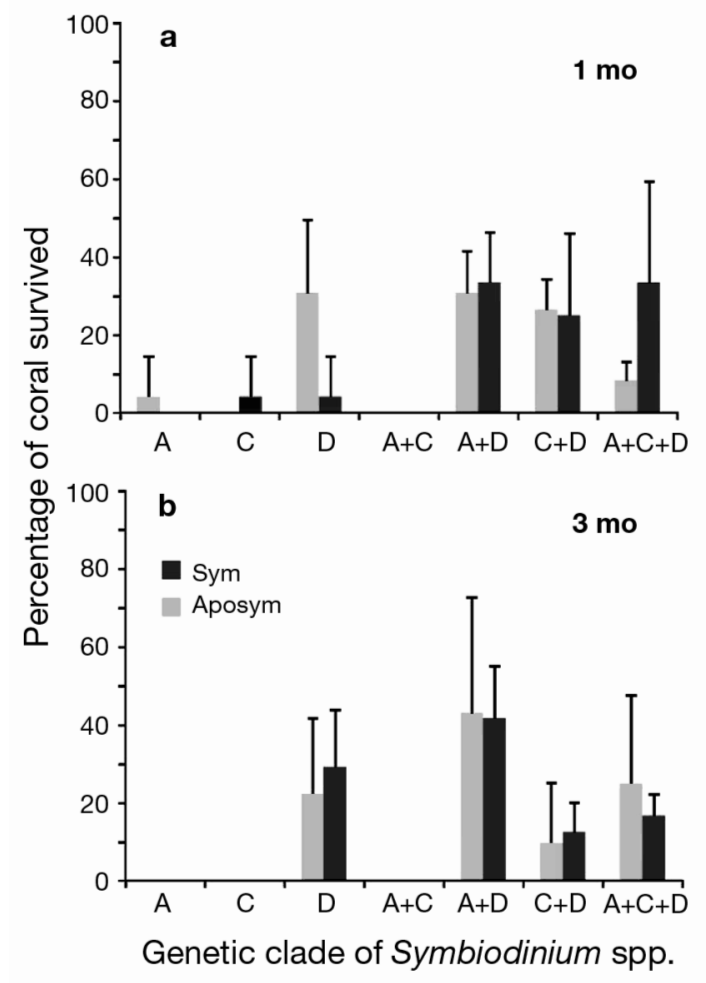

Fig. 5. Mean $(+\mathrm{SD})$ proportion $(\mathrm{n}=6)$ of different symbiont clades in live corals at (a) 1 mo and (b) 3 mo after settlement

boured clade A. The clade composition of Symbiodinium differed between symbiotic and aposymbiotic groups at 1 mo after settlement $(\mathrm{R}=0.045, \mathrm{p}<0.1)$. 'Clade D only' was the dominant Symbiodinium composition in aposymbiotic group, while 'clade A + C + $\mathrm{D}^{\prime}$ was the main Symbiodinium composition in the symbiotic group (Fig. 5a). However, these differences were not significant at 3 mo after settlement $(\mathrm{R}=-0.027, \mathrm{p}>0.1)$ (Fig. 5b).

\section{Light intensity}

As the depth increased, the light photon density decreased; at $18 \mathrm{~m}$ depth it was approximately $30 \%$ of that at $5 \mathrm{~m}$ depth (Table 1). The shade board reduced the light photon density by $10 \%$ at $5 \mathrm{~m}$ and $20 \%$ at $18 \mathrm{~m}$.

\section{DISCUSSION}

The artificial addition of Symbiodinium to coral larvae improved the survival rates of settlers at 1,7 , and 15 mo after settlement. Therefore, the larval-stage Acropora corals that took up the symbiont at an early stage showed increased chances of post-settlement survival, compared with those of coral larvae that did not establish the symbiosis at an early stage. The largest difference in the survival of settled corals between symbiotic and aposymbiotic larvae was at 1 mo after settlement, and the smallest difference was at 15 mo after settlement. Almost all the 'early uptake' settlers survived the first month, whereas on average, more than $40 \%$ of the 'no uptake' settlers died. However, this difference was not significant at 3 mo after settlement. One possible explanation for this is that the number of corals alive after 3 mo was underestimated. The high mortality (approximately $50 \%$ ) over this period could have meant that the number of surviving corals on the observed pieces (i.e. the subsamples from the grid plates) was too small to allow accurate estimates of the total number of corals on the experimental plates. Considering the algal density within the host, it may be that the effect of 'early uptake' on the survival of coral recruits is strongest while the algal density is still low (first month after settlement).

Among the plate treatments, the number of surviving corals was higher for the 'early uptake' group than for the 'no uptake' group in the ' 3 mo shading' treatment, but there was no difference in survival between the 2 groups in the 'seeding only' and ' 7 mo shading' treatments. These results suggest that the early uptake of symbionts enhanced the post-settlement survival rate only when the settlers had insufficient light (less than $120 \mu \mathrm{mol} \mathrm{m} \mathrm{m}^{-2} \mathrm{~s}^{-1}$; Table 1) for a limited period (less than $3 \mathrm{mo}$ ). Such conditions are not uncommon for coral settlers because Acropora larvae tend to settle in crevices and cavities of the reef substratum, and this has the effect of removing them from grazing (Maida et al. 1994). Considering this pattern of larval behaviour, we propose that Acropora corals that actively take up symbionts at the larval stage are more likely to survive after settlement.

Alternatively, the higher survival rate of 'early uptake' juveniles may be due to differences in the genetic types of Symbiodinium harboured by the coral settlers. We compared 2 groups of coral settlers, one that had taken up a cultured strain of clade A at the larval stage, and another that had taken up wild strains from the environmental pool. In fact, both groups of coral settlers mainly harboured clade D Symbiodinium, which was taken up from ambient waters and sediments, and the clade compositions were similar in the 2 groups at 3 mo after settlement. However, clade A was less common in corals derived from aposymbiotic larvae than in those derived from 
symbiotic larvae at $1 \mathrm{mo}$ after settlement. Significant differences in coral survival between the 2 groups were also observed at this time. Although we did not identify the reason for the preferential uptake of clade D in this study, Acropora corals may preferentially acquire clade A symbionts in the initial larval stage ( $\mathrm{H}$. Yamashita et al. unpubl. data), whereas clade D symbionts are selected at the late larval stage and after metamorphosis or settlement. Previous studies showed that the genetic type (i.e. clade) of symbionts affected coral growth and survival; for example, juveniles harbouring clade $\mathrm{C}$ grew more rapidly than those harbouring clade $\mathrm{D}$ (Little et al. 2004, Cantin et al. 2009). In addition, gene expression patterns within corals were grouped according to Symbiodinium genotype (DeSalvo et al. 2010). Clade A Symbiodinium has been found in disturbed environments and has been likened to a 'weed' because of its insensitivity to environmental stresses (Rowan 1998). Based on the result that clade A was found in unhealthy corals, this clade was thought to represent parasitic, rather than mutualistic, symbionts (Stat et al. 2008). However, clade A was also one of the dominant clades in coral recruits (Cumbo et al. 2013, Yamashita et al. 2013), suggesting that this clade may be the dominant type of symbiont under unstable environmental conditions, such as those during the early life stages of the coral or when host corals are in a poor state of health. Also, corals harbouring clade $\mathrm{D}$ were shown to be resistant to thermal stress (Baker 2003, Baker et al. 2004). These findings suggest that the greater survival of the 'early uptake' settlers was due to differences in the genetic type of symbionts. Specifically, the initial acquisition of clades A and D might serve as a preventive defence against various stresses such as unstable irradiance and temperature conditions during juvenile development. Also, it is possible that there is active selection for coral larvae by particular Symbiodinium types. This should be explored in future research.

In field experiments evaluating coral settlement on artificial substrates, one of the main difficulties has been the high initial mortality rate. The grid structure of the settlement plates used in this study meant that more than $10 \%$ of the settled corals survived for 15 mo (except those in the 'shading' treatments) (Fig. 6). This allowed us to analyse long-term postsettlement survival by reducing the effects of factors that influence settler mortality, such as fish grazing and sedimentation (Suzuki et al. 2011b). In a previous study, more coral recruits survived on the $2.5 \mathrm{~cm}$ plates than on the $4 \mathrm{~cm}$ plates (Suzuki et al. 2011b),

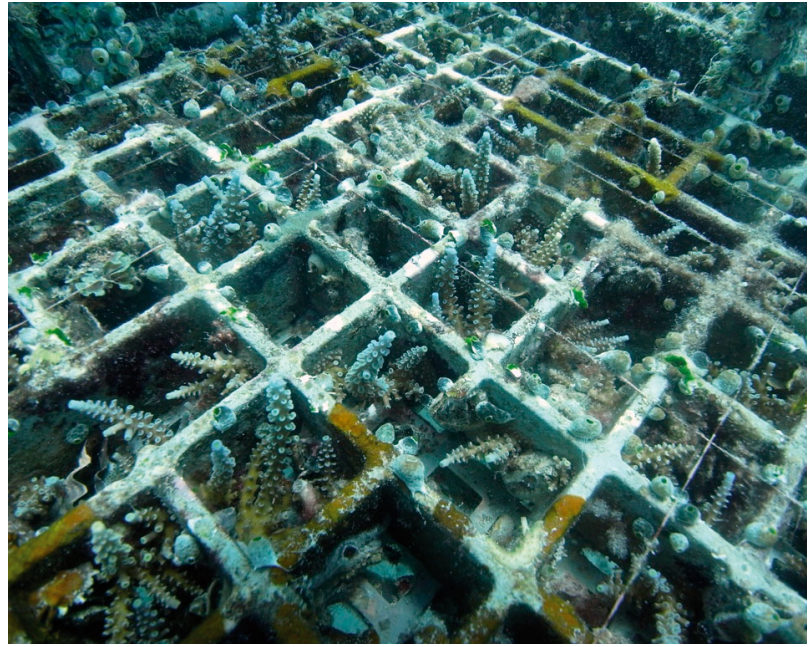

Fig. 6. Live corals 15 mo after settlement on a 'grazing guard only' with 'early uptake' conditioned plate

but we did not observe this difference between the 2 grid sizes in this study. The site of the present study differed from that used in previous studies; the extent of fish grazing and other factors that negatively affect initial survival of coral recruits may vary among different reef habitats.

Our findings shed new light on the ecological role of the early establishment of the coral-Symbiodinium symbiosis. Our results showed that the early uptake of symbionts increased the rate of post-settlement survival of corals. Therefore, early uptake not only promotes long-distance dispersal, but also survival at the early stages of settlement. Reports on corals in the Great Barrier Reef, Australia, suggested that coral larvae adapt to their settlement site via random uptake, rather than selective uptake, of symbionts from ambient sediments (Abrego et al. 2009, Cumbo et al. 2013). In contrast, in the Ryukyu Archipelago of Japan, the dominant Symbiodinium types in juvenile Acropora corals were clades A and D, even though clade $C$ was dominant in the environment pool (e.g. in neighbouring adult corals, sediments, and seawater), suggesting that random uptake did not occur at this site (Yamashita et al. 2013). The clade A strain used in this study was isolated from a wild juvenile Acropora, and the same type of Symbiodinium is also present in the water column at low frequencies (Yamashita \& Koike 2013). In conclusion, even small differences in the timing of uptake ( $2 \mathrm{~d}$ ) of clade A Symbiodinium significantly influenced the clade composition of symbionts at least 1 mo after settlement, and those that took up the symbiont earlier (i.e. $4 \mathrm{~d}$ old larvae) showed a higher post-settlement survival rate. These observations strongly support the idea that the early uptake of 
symbionts is advantageous for corals, even if they are not dispersed over long distances. In future research, we will explore whether this 'early uptake' strategy is species-specific or general among reef corals, considering that there are diverse initial life histories in the coral-algal symbiosis.

Acknowledgements. This study was a part of the Coral Propagation under Severe Environmental Conditions Project of the Fisheries Agency, Japan. We thank Dr. M. Kitano for help with field research. Sampling of corals was exceptionally permitted by the Okinawa Prefectural Government for research use (No. 23-47)

\section{LITERATURE CITED}

Abrego D, Van Oppen MJH, Willis BL (2009) Onset of algal endosymbiont specificity varies among closely related species of Acropora corals during early ontogeny. Mol Ecol 18:3532-3543

> Adams LM, Cumbo VR, Takabayashi M (2009) Exposure to sediment enhances primary acquisition of Symbiodinium by asymbiotic coral larvae. Mar Ecol Prog Ser 377: 149-156

Babcock R, Davies P (1991) Effects of sedimentation on settlement of Acropora millepora. Coral Reefs 9:205-208

Baker AC (2003) Flexibility and specificity in coral-algal symbiosis: diversity, ecology, and biogeography of Symbiodinium. Annu Rev Ecol Evol Syst 34:661-689

Baker AC, Starger CJ, McClanahan TR, Glynn PW (2004) Corals' adaptive response to climate change. Nature 430 : 741

Baria MVB, Guest JR, Edwards AJ, Alino PM, Heyward AJ, Gomez ED (2010) Caging enhances post-settlement survival of juveniles of the scleractinian coral Acropora tenuis. J Exp Mar Biol Ecol 394:149-153

Birrell CL, McCook LJ, Willis BL (2005) Effects of algal turfs and sediment on coral settlement. Mar Pollut Bull 51: 408-414

> Cantin NE, van Oppen MJH, Willis BL, Mieog JC, Negri AP (2009) Juvenile corals can acquire more carbon from high-performance algal symbionts. Coral Reefs 28: 405-414

Coles SL, Brown EK (2007) Twenty-five years of change in coral coverage on a hurricane impacted reef in Hawai'i: the importance of recruitment. Coral Reefs 26:705-717

Cowen RK, Lwiza KMM, Sponaugle S, Paris CB, Olson DB (2000) Connectivity of marine populations: Open or closed? Science 287:857-859

Cumbo VR, Baird AH, van Oppen MJH (2013) The promiscuous larvae: flexibility in the establishment of symbiosis in corals. Coral Reefs 32:111-120

> DeSalvo MK, Sunagawa S, Fisher PL, Voolstra CR, IglesiasPrieto R, Medina M (2010) Coral host transcriptomic states are correlated with Symbiodinium genotypes. Mol Ecol 19:1174-1186

Edmunds PJ (2000) Patterns in the distribution of juvenile corals and coral reef community structure in St. John, US Virgin Islands. Mar Ecol Prog Ser 202:113-124

Glassom D, Zakai D, Chadwick-Furman NE (2004) Coral recruitment: a spatio-temporal analysis along the coast- line of Eilat, northern Red Sea. Mar Biol 144:641-651

Harii S, Yasuda N, Rodriguez-Lanetty M, Irie T, Hidaka M (2009) Onset of symbiosis and distribution patterns of symbiotic dinoflagellates in the larvae of scleractinian corals. Mar Biol 156:1203-1212

Harii S, Yamamoto M, Hoegh-Guldberg O (2010) The relative contribution of dinoflagellate photosynthesis and stored lipids to the survivorship of symbiotic larvae of the reef-building corals. Mar Biol 157:1215-1224

Hayashibara T, Ohike S, Kakinuma Y (1997) Embryonic and larval development and planula metamorphosis of four gamete-spawning Acropora (Anthozoa, Scleractinia). Proc 8th Int Coral Reef Symp, Panama 2:1231-1236

- Hayashibara T, Iwao K, Omori M (2004) Induction and control of spawning in Okinawa staghorn corals. Coral Reefs 23:406-409

> Hirose M, Kinzie R, Hidaka M (2001) Timing and process of entry of zooxantellae into oocytes of hermatypic corals. Coral Reefs 20:273-280

$>$ Hughes TP, Tanner JE (2000) Recruitment failure, life histories, and long-time decline of Caribbean corals. Ecology 81:2250-2263

- Hughes TP, Baird AH, Dinsdale EA, Moltschaniwskyj NA, Pratchett MS, Tanner JE, Willis BL (1999) Patterns of recruitment and abundance of corals along the Great Barrier Reef. Nature 397:59-63

> Hughes TP, Bellwood DR, Folke C, Steneck RS, Wilson J (2005) New paradigms for supporting the resilience of marine ecosystems. Trends Ecol Evol 20:380-386

Jones GP, Milicich MJ, Emslie MJ, Lunow C (1999) Selfrecruitment in a coral reef fish population. Nature 402: 802-804

> Jones GP, Almany GR, Russ GR, Sale PF, Steneck RS, van Oppen MJH, Willis BL (2009) Larval retention and connectivity among populations of corals and reef fishes: history, advances and challenges. Coral Reefs 28:307-325

Little AF, van Oppen MJH, Willis BL (2004) Flexibility in algal endosymbioses shape growth in reef corals. Science 304:1492-1494

Maida M, Coll JC, Sammarco PW (1994) Shedding new light on scleractinian coral recruitment. J Exp Mar Biol Ecol 180:189-202

> Marlow HQ, Martindale MQ (2007) Embryonic development in two species of scleractinian coral embryos: Symbiodinium localization and mode of gastrulation. Evol Dev 9:355-367

> Morse ANC, Iwao K, Baba M, Shimoike K, Hayashibara T, Omori M (1996) An ancient chemosensory mechanism brings new life to coral reefs. Biol Bull (Woods Hole) 191: 149-154

> Muscatine L, McCloskey LR, Marian RE (1981) Estimating the daily contribution of carbon from zooxanthellae to coral animal respiration. Limnol Oceanogr 26:601-611

Nozawa Y (2008) Micro-crevice structure enhances coral spat survivorship. J Exp Mar Biol Ecol 367:127-130

> Nozawa Y, Harrison PL (2008) Temporal patterns of larval settlement and survivorship of two broadcast-spawning acroporid corals. Mar Biol 155:347-351

Pochon X, Gates RD (2010) A new Symbiodinium clade (Dinophyceae) from soritid foraminifera in Hawai'i. Mol Phylogenet Evol 56:492-497

Poulin E, Palma AT, Leiva G, Narvaez D, Pacheco R, Navarrete SA, Castilla JC (2002) Avoiding offshore transport of competent larvae during upwelling events: the case of the gastropod Concholepas concholepas in Central 
Chile. Limnol Oceanogr 47:1248-1255

Rinkevich B (1989) The contribution of photosynthetic products to coral reproduction. Mar Biol 101:259-263

Rowan R (1998) Diversity and ecology of zooxanthellae on coral reefs. J Phycol 34:407-417

Sammarco PW, Andrews JC (1988) Localized dispersal and recruitment in Great Barrier Reef corals: the Helix experiment. Science 239:1422-1424

Sampayo EM, Ridgwat T, Bongaerts P, Hoegh-Guldberg O (2008) Bleaching susceptibility and mortality of corals are determined by fine-scale differences in symbiont type. Proc Natl Acad Sci USA 105:10444-10449

Schwarz JA, Krupp DA, Weis VM (1999) Late development and onset of symbiosis in the scleractinian coral Fungia scutaria. Biol Bull (Woods Hole) 196:70-79

Shanks AL, Shearman RK (2009) Paradigm lost? Cross-shelf distributions of intertidal invertebrate larvae are unaffected by upwelling or downwelling. Mar Ecol Prog Ser 385:189-204

Stat M, Morris E, Gates RD (2008) Functional diversity in coral-dinoflagellate symbiosis. Proc Natl Acad Sci USA 105:9256-9261

Suzuki G, Arakaki S, Hayashibara T (2011a) Rapid in situ settlement following spawning by Acropora corals at

Editorial responsibility: Charles Birkeland,

Honolulu, Hawaii, USA
Ishigaki, Japan. Mar Ecol Prog Ser 421:131-138

Suzuki G, Kai S, Yamashita H, Suzuki K, Iehisa Y, Hayashibara T (2011b) Narrower grid structure of artificial reef enhances initial survival of in situ settled coral. Mar Pollut Bull 62:2803-2812

Trench RK (1987) Dinoflagellates in non-parasitic symbioses. In: Taylor FJR (ed) The biology of the dinoflagellates. Wiley-Blackwell, Oxford, p 530-570

Underwood JN, Smith LD, van Oppen MJH, Gilmour JP (2009) Ecologically relevant dispersal of corals on isolated reefs: implications for managing resilience. Ecol Appl 19:18-29

Wilson J, Harrison P (2005) Post-settlement mortality and growth of newly settled reef corals in a subtropical environment. Coral Reefs 24:418-421

Yamashita H, Koike K (2013) Genetic identity of free-living Symbiodinium obtained over a broad latitudinal range in the Japanese coast. Phycol Res 61:68-80

> Yamashita H, Suzuki G, Hayashibara T, Koike K (2011) Do corals select zooxanthellae by alternative discharge? Mar Biol 158:87-100

> Yamashita H, Suzuki G, Hayashibara T, Koike K (2013) Acropora recruits harbor 'rare' Symbiodinium in the environmental pool. Coral Reefs 32:355-366

Submitted: March 4, 2013; Accepted: August 31, 2013 Proofs received from author(s): November 25, 2013 